\title{
Teaching High Schoolers How Science Works
}

\author{
The introduction of quantum physics to high school lessons offers
} educators the opportunity to teach students about how scientific advances are made.

\section{By Katherine Wright}

F ive years ago, quantum physics was taught to high school students in the Netherlands for the first time (see Synopsis: How High Schools Teach Quantum Physics). For Kirsten Stadermann, a high school science teacher and physics education Ph.D. student in the Netherlands, this change brought with it a new challenge-teaching a subject she hadn't taught before. But it also offered an opportunity to design a curriculum that incorporates lessons about the human endeavor behind scientific progress-something termed the nature of science. Stadermann and her advisor Martin Goedhart, who both work at the University of Groningen, Netherlands, created nature-of-science teaching materials and worked with other teachers to implement them in the

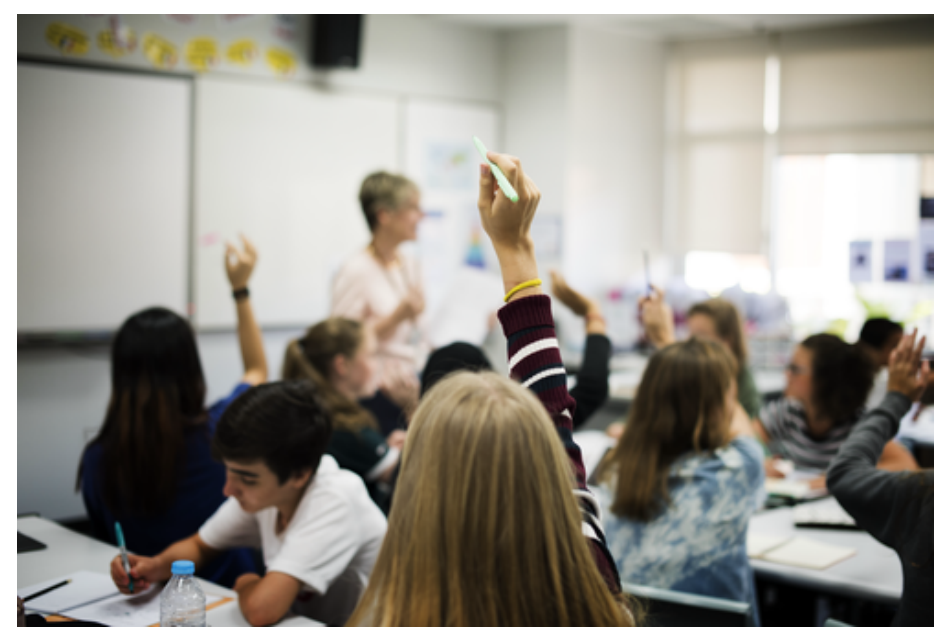

Teachers in the Netherlands have been trialing a "nature-of-science" curriculum in their classes. Credit: rawpixel.com/stock.adobe.com classroom. They have now published the results of those efforts, highlighting how the teachers used the materials in their classes [1].

Science is more than a body of knowledge; it is a collective human effort to build a coherent story and understanding of our world. Scientists share certain beliefs and follow certain rules. They create theories and conduct experiments to build on previous findings, overturning those that don't stand up to new data, such as Bohr's model of the atom, and strengthening those that do, such as Heisenberg's uncertainty principle. Controversies abound (see The Venus Phosphine Debate Continues) and mysteries endure (see Viewpoint: The Relentless Hunt for Dark Matter).

But these details of how science is done are missing in most physics courses, where the curricula typically focus on teaching long-established facts, such as Newton's 335-year-old law of gravitation. Students can come away with the message that scientific knowledge is absolute and its laws infallible, Stadermann says. This sentiment is echoed by educational researcher Magdalena Kersting of the University of Oslo, Norway, who was not involved in the new study. "Students can easily get the idea that physics is old, boring, and outdated-and that physics has no relevance to their lives," Kersting says.

For Stadermann, introducing quantum physics into her curriculum offered an opportunity to change that. She decided to incorporate nature-of-science-related learning goals into her own materials. She then recruited ten high school teachers to 


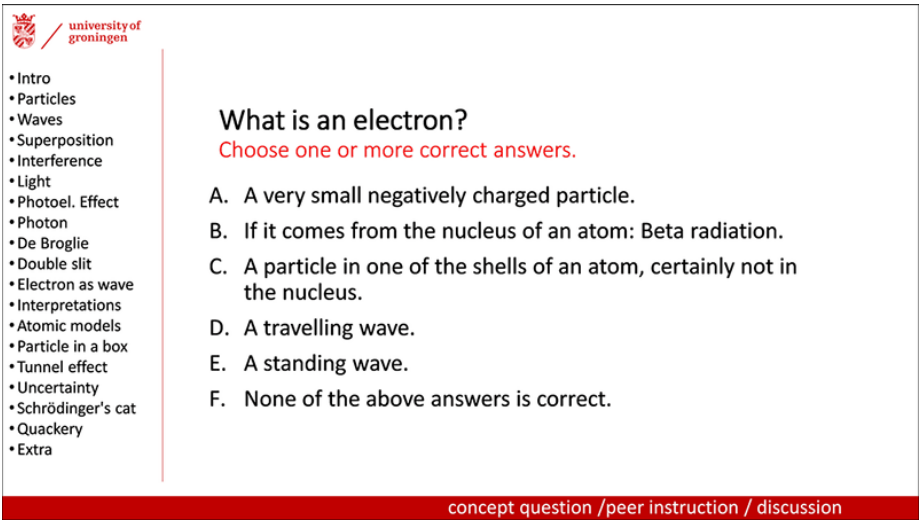

Example of one of Stadermann's slides.

Credit: H. K. E. Stadermann and M. J. Goedhart [1]

try out the materials, sitting in on their lessons and conducting interviews with them to see what they thought.

Stadermann's learning materials consist of 142 presentation slides that cover all aspects of the Dutch quantum physics curriculum. Mixed in with the lessons on the photoelectric effect and Schrödinger's cat are resources, such as discussion prompts and video links, for teaching the nature of science. For example, a slide entitled "What is an electron?" has a multiple-choice question that educators can use to stimulate discussions on topics ranging from the role and validity of scientific models to the ability of humans to understand reality (Fig. 2).

The teachers in the study were given the slides and an introduction on how to use them. Stadermann's interviews, along with data she took from watching classes, show that all the teachers except one-the only one with a Ph.D. in physics-incorporated nature-of-science slides into their lessons. Most of them did that through whole-class discussions, where students debated their ideas. The most popular debate topics were "the role of models" and "controversies."

The teachers who used the materials said that discussing the nature of science sparked students' interest in quantum physics and enhanced their understanding of the key concepts. It also provided a way to bring the human element of science-the scientists, their struggles, and their achievements-into lessons. With this initial pilot done, Stadermann is now working on making her learning materials available to all via a website. She also hopes that the positive outcomes of the study will encourage publishers to incorporate nature-of-science elements into their high school science textbooks.

"Physics education can only be as good as its instructors, so I think the great potential of the study is to help physics teachers improve their instructional practices in quantum physics through nature of science," Kersting says.

Stadermann also sees broader implications for the study. Teaching students about how science works should help them interpret findings reported in the media and understand, for example, why advice on wearing masks has changed over the course of the COVID-19 pandemic. It's important, now more than ever, that people are aware that scientific understanding can evolve and that this evolution is a good thing, she says. "It's how science should be."

Katherine Wright is the Deputy Editor of Physics.

\section{REFERENCES}

1. H. K. E. Stadermann and M. J. Goedhart, "Why and how teachers use nature of science in teaching quantum physics: Research on the use of an ecological teaching intervention in upper secondary schools," Phys. Rev. Phys. Educ. Res. 17, 020132 (2021). 